\title{
Social Responsibility in a Bilateral Monopoly with Downstream Convex Technology
}

\author{
Luciano Fanti ${ }^{1} \cdot$ Domenico Buccella $^{2}$ (D)
}

Received: 17 October 2019 / Revised: 30 May 2020

Accepted: 9 June 2020 / Published online: 28 June 2020

(C) The Author(s) 2020, corrected publication 2020

\begin{abstract}
This paper shows that, in a bilateral monopoly with consumer-friendly social concerns, only the downstream firm is always incentivized to adopt corporate social responsibility (CSR) if it has decreasing returns to the input, leading to a Pareto-superior outcome in equilibrium. This occurrence differs from a standard linear bilateral monopoly in which, if the upstream (downstream) firm commits itself to CSR before the downstream (upstream) does, then both firms improve profits, while they do not deviate from pure profitmaximization if CSR levels are simultaneously chosen. Straightforward policy and empirical implications are offered, and this paper argues that the presence of CSR-type firms crucially depends on technology.
\end{abstract}

Keywords Bilateral monopoly $\cdot$ Corporate social responsibility

JEL Classification D21 $\cdot \mathrm{L} 12 \cdot \mathrm{L} 22 \cdot \mathrm{M} 14$

\section{Introduction}

During the last decades, the adoption of corporate social responsibility (CSR) activities has become a global business practice. In 2002, KPMG surveyed the top 100 companies in 45 countries, disclosing that 23 percent of them declared the accomplishment of CSR activities in their financial reports; those figures increase to 73 percent in 2015. Moreover, in the same time

Domenico Buccella

buccella@kozminski.edu.pl

Luciano Fanti

luciano.fanti@unipi.it

1 Department of Economics and Management, University of Pisa, Via Cosimo Ridolfi, 10, I56124 Pisa, PI, Italy

2 Department of Economics, Kozminski University, Jagiellońska Street, 57/59, 03301 Warsaw, Poland 
period, the Global Fortune Index (which includes the world's 250 largest companies) has more than doubled those figures, from 45 to 92 percent (KPMG 2005, 2015).

The booming expansion of CSR has raised questions among scholars and policy makers, thus spurring the debate on the motives pushing companies to engage in socially concerned activities. Interestingly, however, in some vertically related industries, an asymmetric attitude toward CSR has been observed among upstream and downstream firms. For instance, on November 2017, leading carmakers including Volkswagen and Toyota pledged to sustain socially responsible standards in their purchases of minerals for an expected boom in electric vehicle production. However, talks with major cobalt producers (including Glencore, one of the largest globally diversified natural resources company), which are barely engaged in CSR in activities, ended without a deal on this issue (Reuters, 2017).

In this paper, we start from the basic model of duopolistic Cournot competition, in which it is easy to show that firms - which maximize short-run profits - always reduce their profits by introducing social concerns in their objectives, for instance, under the form of an "interest" for the welfare of consumers, and we pose the following research question: how do firms' attitudes toward CSR activities depend on the feature of production function in a vertically related industry?

Our reference point is the contribution of Brand and Grothe (2015), which analyzes the choice of CSR engagement in the upstream and downstream firms in a standard, linear bilateral monopoly. Those authors, as the majority of the literature on CSR, assume constant returns to input (i.e., a one-on-one relationship between input and output). They find that CSR may emerge only if the upstream firm is the Stackelberg leader in the choice of the CSR levels, and the weight given to the consumer surplus by the downstream firm is precisely one-third and half of that given by the upstream firm.

Given the specificity of the predictions of Brand and Grothe (2015), we question if the alteration of the assumption with regard to the technology in place in the supply chain will modify such results. Thus, in our framework, the constant return to input assumption is relaxed and substituted by a decreasing return to input, while the rest of the Brand and Grothe's (2015) model is kept unaltered. In detail, we assume increasing marginal costs in line with the shortrun context of any Cournot model: indeed, according to the first principles of economics, in the short run, some factors are fixed with remaining factors subject to diminishing returns, so the short-run marginal cost increases in output. With regard to the labor costs, typical arguments for the existence of rising marginal costs are, for instance, the additional costs of overtime work and the higher cost of bringing into use older equipment to meet the additional demand. ${ }^{1}$

The main findings of the paper are as follows. First, in a vertical industry in which the upstream firm has linear technology with constant returns while the downstream firm shows decreasing returns to input, firm owners may earn higher profits at equilibrium, adopting CSR behaviors. Second, only the downstream firm finds it optimal to be of CSR type and strongly engaged in the welfare of consumers, thus reversing the standard result obtained by Brand and Grothe (2015) in a standard bilateral monopoly with overall linear technology. Nonetheless, the profit-seeking upstream firm benefits from the consumer-friendly CSR of its downstream firm, leading to a Pareto-superior outcome.

\footnotetext{
${ }^{1}$ Making use of US manufacturing data for 1957-1983, Bils (1987) shows that a short-run increase in production-worker employment of 10 percent was associated with a marginal cost rise of about 2.4 percent, mostly due to overtime payments, because employment is not perfectly flexible. As a consequence, marginal costs are increasing and returns are decreasing.
} 
In the next section, we present a review of the related literature. Then, in Section 3, we introduce the basic ingredients of the model with unions and the cooperative choices of CSR activities. Then, Section 4 presents the equilibrium outcomes of the model without CSR, compares the outcomes of the models, and derives the main results. The last section sums up our findings, offering some policy and empirical insights.

\section{Literature Review}

A typical feature shared by several articles is the assumption of CSR activities in terms of a maximization of an objective function, which is a weighted sum of profit and consumer surplus; i.e., social responsibility takes the form of consumer-friendly activities. However, among those contributions, a typical difference concerns whether and how such CSR activities are chosen. On the one hand, the levels of CSR may be exogenously given for both firms, or only one firm chooses the level of CSR while other firms remain profit-seeking (e.g., Kopel, 2009; Kopel and Brand, 2012; Goering 2007, 2009, 2012, 2014; Brand and Grothe, 2013, who focus on the effects of firms' CSR on competition under managerial delegation; Lambertini and Tampieri 2012, 2015, and Lambertini, Palestini, and Tampieri, 2016, who focus on environmental outcomes; Fanti and Buccella, 2017a,b; Leal et al., 2019, who study the impact of firms' CSR on market integration), and on the other hand, the CSR levels are endogenously chosen by profit-maximizing firms' owners for strategic reasons in oligopolistic contexts (i.e., in a standard Cournot duopoly market), although few authors study the endogenous strategic choice of the CSR parameter (e.g., Hino and Zennyo, 2017; Nakamura, 2018; Planer-Friedrich and Sahm, 2018, 2020; Fanti and Buccella, 2017b Supplement, c). ${ }^{2}$ Hino and Zennyo (2017) analyze endogenous decision-making behavior with regard to the level of CSR in a delegation game with Cournot-Stackelberg competition. They show that the follower can derive a greater profit than the leader and achieve maximum profit when firms sequentially choose their CSR level. Based on Hino and Zennyo (2017), Nakamura (2018) investigates the endogenous choice of strategic contracts in an asymmetric duopoly with substitute goods in which a managerial firm offers a standard sales delegation contract, and a CSR firm offers a managerial scheme based on a linear combination of social welfare and quantity as its managerial delegation contract. In particular, the author focuses on how the equilibrium market structure changes from the standard case in which both firms adopt sales delegation contracts to the case in which one firm engages in CSR, after the firms' owners select their strategic contracts. Planer-Friedrich and Sahm (2018) show that firms prefer to care for all consumers rather than for its own customers only, choosing positive levels of CSR, but at equilibrium, choosing CSR reduces firms' profits.

However, independent of the strategic motivations for adopting CSR behaviors (which, as highlighted above, lead to lower profits at the market equilibrium), some recent papers have shown that the aim of maximizing profits can be a motive for the firm's engagement in CSR, as the neoclassical economics point of view is required because the adoption of CSR may increase profits of all firms at the market equilibrium. Fanti and Buccella (2017b, Supplement) study the situation in which firms' owners non-cooperatively select their endogenous level of social concerns. Those authors find that, when goods are substitutes, a unique subgame perfect

\footnotetext{
${ }^{2}$ Siegel and Vitaliano (2007) and Fernández-Kranz and Santaló (2010) provide some empirical confirmations that firms' social responsibility can be strategically chosen.
} 
Nash equilibrium exists in which both firms engage in CSR, but this equilibrium is Pareto inefficient; a standard prisoner's dilemma thus arises. Indeed, Fanti and Buccella (2017c), also introducing managerial delegation (i.e., owners delegate output decisions to a manager), show that, in the subgame perfect Nash equilibrium, both firms are CSR-type and, in addition, the presence of CSR activities improves the firms' profitability while harming the welfare of consumers and society. This result is in contrast to the conventional wisdom under nonmanagerial firms. Moreover, Fanti and Buccella (2018) show that, when firms noncooperatively compete on CSR in network industries, the classical conventional prisoner's dilemma result in standard industries (i.e., to have social concerns is the Nash equilibrium but it is harmful for firms' profits) vanishes, and for adequately strong network effects, the equilibrium in which both firms engage in CSR is more profitable than simple profit-seeking. When firms cooperatively choose the profit-maximizing level of CSR, a profit-maximizing CSR level does exist, provided that network effects are adequately strong.

While all the aforementioned contributions deal with the standard Cournot duopoly, another branch of this literature studying the strategic content of the CSR choices focuses on a vertical structure of the industry and studies the impact of firms' social concern on that. The current paper focuses more on this aspect. In particular, in a bilateral monopoly model, Goering (2012) and Brand and Grothe (2013) focus on a perfectly coordinated supply chain channel; in such a case, the double marginalization - early investigated by Spengler (1950) - is eliminated by construction through the assumption that the upstream firm absorbs the whole retailer's profit with an optimal two-part tariff. While the former assumes that either the upstream firm or the downstream firm can be socially concerned and finds that CSR reduces a firm's profit, the latter authors extend the analysis to the case in which both firms are socially concerned and show that the downstream firm does not have any incentive to be socially concerned, because all actions are neutralized by the upstream firm through the two-part tariff. Goering (2014) assumes that the upstream firm, which is strictly profit-seeking, will select a two-part contract, consisting of a wholesale price for the goods and level of CSR (which its downstream firm has to include in its business activity) that maximizes its profits, showing that a CSR contract can be used in place of the two-part tariff scheme to coordinate optimally the marketing channel.

Brand and Grothe (2015), unlike Goering (2012) and Brand and Grothe (2013), relax the assumption of perfect channel coordination and, unlike Goering (2014), assume that both the upstream firm and the downstream firm maximize the socially responsible objectives. Those authors show that, when both firms simultaneously choose their level of social responsibility or the downstream firm first commits on the social responsibility, both firms do not have an incentive to deviate from pure profit maximization, while if the choice of the upstream firm on social concerns is prior to that of the downstream firm then, at the equilibrium, both firms endogenously decide to follow CSR rules and benefit more than otherwise.

A recent paper by Chen et al. (2016), still examining the influence of CSR strategy in vertically related markets, examines the downstream firm's effort and the different pricing rule under successive duopoly, assuming that downstream firms are not directly concerned with CSR; however, they need to choose the optimal efforts to keep or even improve the sales quantity or quality of intermediate goods purchased from the upstream firms, while the upstream firms have CSR concerns, showing that such a concern may reduce the total surplus of the four firms and social welfare. Finally, extending Brand and Grothe's (2015) contribution, García et al. (2018) investigate CSR in a linear bilateral monopoly with cost-reducing $R \& D$ investment and the endogenous timing game. They find that (1) the retailer (downstream firm) always engages in CSR while the manufacturer (upstream firm) adopts CSR only if it 
moves first within a sequential game and (2) two sequential equilibria arise, but the upstream commitment to CSR is the payoff-dominant one.

The results from Brand and Grothe (2015) show that, in a vertical industry, the owners of both firms may choose to be socially responsible, simply because their profits increase (that is, without owners' altruism or stakeholders' pressures). Therefore, several empirical works have started investigating the correlation between CSR activities and profitability performances. On the whole, the results have been mixed or contradictory, even within the same study. It follows that, at the current stage, there is a lack of an unambiguous, general consensus. The vast majority of scholars has identified either an exclusive negative (see, e.g., Davidson et al. 1987; Davidson and Worrel, 1988; Bromiley and Marcus, 1989; Chen et al. 2018) or doubtfully empirical (e.g., Ingram and Frazier, 1983; Aupperle et al., 1985; Bhardwaj et al., 2018) evidence. However, a growing number of empirical works have revealed a positive link between the CSR and their financial performance (e.g., Griffin and Mahon, 1997; Roman et al., 1999; Waddock and Graves, 1997; Lee and Jung, 2019). Focusing on the relationship between performance and CSR in downstream firms, empirical evidence is provided by Schramm-Klein et al. (2015), who, through a survey among downstream firms and applying partial least squares structural equation modeling, argue that CSR generally has positive effects on downstream firm performance, despite the cost associated with CSR implementation.

\section{The Model}

We develop a standard linear bilateral monopoly framework, where $p$ is the market price for the final product and $q$ is the final product's quantity. The upstream firm (U) sells its quantity $m$ at the wholesale price $c$ to the downstream firm (D) before the downstream firm sells the products to the consumer. We denote $v$ as the constant marginal cost of production in the upstream firm. On the other hand, the downstream firm exhibits decreasing returns to scale production function in the input:

$$
q=\sqrt{m}
$$

where $m$ is the input the downstream firm employs. In addition to the manufactured input cost, the downstream firm must face also a constant marginal (e.g., labor) cost, $w$.

Given the outlined assumptions, the monopolist upstream firm's profit function is:

$$
\pi^{U}=(c-v) m=(c-v) q^{2}
$$

withc $>v>0$. The monopolist downstream firm faces the following linear inverse demand function:

$$
p=a-q .
$$

The monopolist downstream firm's profit function ${ }^{3}$ is:

$$
\pi^{D}=(p-w) q-c m=(a-q-w-c q) q
$$

\footnotetext{
${ }^{3}$ Of course, it might be that (1) the upstream firm presents decreasing returns to scale while the downstream firm has constant returns to scale and (2) both the upstream and the downstream firms have decreasing returns to scale. Those cases are worth analyzing in future research.
} 
with $a>w>0$; i.e., the highest final consumers' willingness to pay has to be larger than the downstream marginal labor cost of production. In line with the recent established literature (e.g., Goering 2007, 2008, 2012; Lambertini and Tampieri, 2015; Brand and Grothe, 2015), the model considers the fact that social concerns can be interpreted as taking care of the welfare of consumers (consumers' friendliness). Therefore, the characteristic of a CSR firm is to be responsive to the consumer surplus, which is, as known,

$$
C S=\frac{q^{2}}{2} .
$$

As a consequence, each consumer-friendly firm is supposed, in its objective, to maximize its profits plus a fraction of the consumer surplus, which represents the firm's social concern, or care for consumers. Thus, the CSR-type firm's objective function can be translated into a parameterized combination of profits and consumers' surplus.

It follows that the objective function of the upstream firm $\left(W^{U}\right)$ is

$$
W^{U}=\pi^{U}+k C S=(c-v) q^{2}+k \frac{q^{2}}{2},
$$

where $k \in[0,1]$ is the weight the upstream firm assigns to consumer surplus. On the other hand, the objective function of the downstream firm $\left(W^{D}\right)$ is

$$
W^{D}=\pi^{D}+r C S=(a-q-w-c q) q+r \frac{q^{2}}{2}
$$

where $r \in[0,1]$ is the weight the downstream firm assigns to consumer surplus. ${ }^{4}$

The downstream firm chooses the output level $(q)$ by maximizing its objective function, and the upstream firm chooses the input price $(c)$ by maximizing its objective function. However, notice that firms consider only profits when choosing the level of social concern. Brand and Grothe (2015) argue that the rationale for this is that firms must "survive" in the long run; i.e., firms have to generate positive profits to remain operative in markets. Alternatively, another reason is that a non-negative profit restriction must be imposed while maximizing the objective functions with respect to the level of social concern, input price, and output. Finally, another explanation is that owners who demonstrate social concerns also achieve higher profits, in line with the Friedmanian (Friedman, 1970) standpoint that the maximization of profits to shareholders is the only social responsibility of businesses. The game is structured as a three-stage game. At stage 1, owners of upstream firm and downstream firm non-cooperatively decide the weight of consumer surplus, $k$ and $r$, for the objective function, maximizing their own profits, according to three different sequence of moves: (i) $\mathrm{U} \rightarrow \mathrm{D}$ : the upstream firm chooses $k$ prior to the choice of $r$ by downstream firm; (ii) U\&D: the upstream firm and the downstream firm simultaneously choose $k$ and $r$; (iii) $\mathrm{D} \rightarrow \mathrm{U}$ : the downstream firm chooses $r$ prior to the upstream firm's choice of $k$.

At stage 2, the upstream firm fixes the input price. Then, at stage 3, as usual, the downstream firm chooses output with a CSR objective. As usual, the game is solved through backward induction. The sequence of moves for this game is illustrated in Fig. 1.

At the third stage, the maximization of the downstream firm objective function in (7) leads to the following output function:

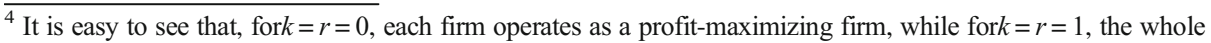
consumer surplus is considered in the firm's objective function.
} 


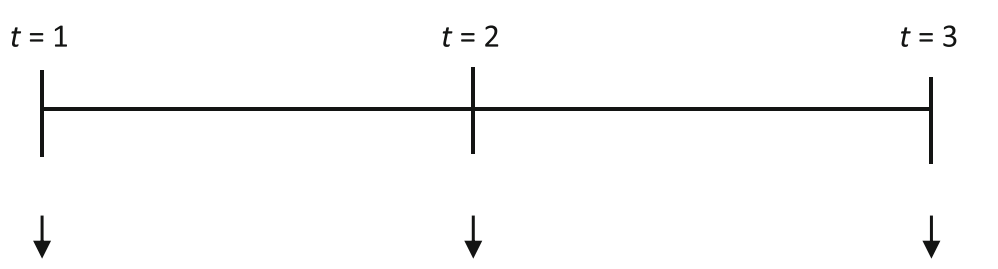

Owners of upstream and downstream firms decide non-cooperatively the weights $k$ and $r$, respectively

U->D: upstream firm chooses $k$ prior to the choice of $r$ by the downstream

U\&D: upstream and downstream firms choose simultaneously $k$ and $r$

D->U: downstream chooses $r$ prior to the choice of $k$ by upstream firm

Fig. 1 Sequence of moves
The upstream firm chooses the input price maximizing its CSR objective function
The downstream firm chooses output $q$ to maximize its CSR objective function

$$
q(c, r)=\frac{a-w}{2(1+c)-r}
$$

At the second stage, after substitution of (8) in (6), the upstream firm maximizes its objective function (6) with respect toc, which straightforwardly leads to the input price as a function of the CSR parameters:

$$
c(k, r)=\frac{2(2 v+1)-2 k-r}{2}
$$

From (9), one notes that an increase in the downstream firm level of CSR engagement leads the input price of the upstream firm to decrease. The rationale for this result is as follows. The more the downstream firm engages in CSR, the more output it produces in the retail market. On the one hand, the demand function of the input market shifts upward, and this would enable the upstream firm to increase its input price. On the other hand, the downstream firm's CSR activity pushes the upstream firm's production on a more elastic point of its demand (see Appendix). Given that the upstream firm's output expansion caused by the downstream firm's CSR ( $m=q^{2}, \frac{\partial q^{2}}{\partial r}>0$ ) also increases its production costs (due to the convex technology), and given the higher price elasticity of demand, to increase total revenues (and therefore profits), 
the upstream firm has to lower its input price, with a price reduction stronger than in the case without the downstream firm's CSR.

Substituting (9) in (8), we obtain the final quantity as a function of the CSR parameters:

$$
q(k, r)=\frac{a-w}{2[2(1+v)-k-r]}
$$

Substituting backwards (9) and (10), we obtain both firms' profits as function of only CSR parameters:

$$
\begin{gathered}
\pi^{U}(k, r)=\frac{[2(1+v)-2 k-r](a-w)^{2}}{8[2(1+v)-k-r]^{2}} \\
\pi^{D}(k, r)=\frac{[4(1+v)-2 k-3 r](a-w)^{2}}{8[2(1+v)-k-r]^{2}}
\end{gathered}
$$

We now address the stage of the decision on the CSR parameters. Let us begin with the case $\mathrm{U} \rightarrow \mathrm{D}$. Under this sequence, the upstream firm decides whether to engage in CSR prior to the corresponding downstream firm's decision. The solutions of this stage are given by the following Lemmas.

Lemma 1. The downstream firm sets a CSR parameter at the level $r=r^{\circ}$, whose values depend on the choice regarding the $k$ level by the upstream firm.

Proof: Differentiating the downstream firm profits, one obtains:

$$
\left.\frac{\partial \pi^{D}}{\partial r}\right|_{U \rightarrow D}=\frac{[2(1+v)-k-3 r](a-w)^{2}}{8[2(1+v)-k-r]^{3}} .
$$

The sign of this derivative depends on the terms in bracket in the numerator, from which one gets that:

$$
\left.\frac{\partial \pi^{D}}{\partial r}\right|_{U \rightarrow D} \frac{>}{<} 0 \Leftrightarrow r \frac{<}{>} r^{\circ}=\frac{2(1+v)-k}{3}
$$

Lemma 2. The upstream firm, taking into account the decision of the downstream firm on $r=$ $r^{\circ}$, chooses to remain a profit-seeking firm (i.e., $k=0$ ).

Proof: Differentiating the upstream firm profits, one gets

$$
\left.\frac{\partial \pi^{U}}{\partial k}\right|_{U \rightarrow D}=\frac{3[5 k+2(1+v)](a-w)^{2}}{32[k-2(1+v)]^{3}}<0, \quad \forall k \in[0,1]
$$

Under the sequence U\&D, both firms' owners decide independently and simultaneously on their CSR parameters, leading to the following Lemmas. 
Lemma 3. Only the downstream firm decides a positive engagement in CSR activities setting $r=r *$.

Proof: this is straightforwardly derived by observing each derivative of profits with respect to the unique CSR parameter:

$$
\left.\frac{\partial \pi^{U}}{\partial k}\right|_{U \& D}=-\frac{k(a-w)^{2}}{4[2(1+v)-k-r]^{3}} \leq 0, \quad \forall k \in[0,1],
$$

and

$$
\left.\frac{\partial \pi^{D}}{\partial r}\right|_{U \& D}=\frac{[2(1+v)-k-3 r](a-w)^{2}}{8[2(1+v)-k-r]^{3}} \frac{\geq}{<} 0 \Leftrightarrow r \frac{<}{>} r^{\circ}=\frac{2(1+v)-k}{3}
$$

Therefore, the downstream firm, given the upstream firm's choice of remaining profit-seeking $(k=0)$, selects the optimal (profit-maximizing) CSR parameter at the following level:

$$
r^{*}=\frac{2(1+v)}{3}
$$

Remark: By inspection of (13), we observe that the downstream firm always chooses to take into account in its objective at least two-thirds of the consumer surplus. Because this weight increases with the marginal cost of input production, it follows that, when the latter is sufficiently high, even a weight of the consumer surplus larger than the unity (and then, than own profits) may be optimal for the selfish downstream firm.

Finally, under the sequence $\mathrm{D} \rightarrow \mathrm{U}$, the downstream firm decides whether to engage in CSR prior to the corresponding upstream firm's decision. Under this sequence, the following holds.

Lemma 4. The upstream firm never engages in CSR activities.

Proof: Differentiation of the upstream firm profits leads to

$$
\left.\frac{\partial \pi^{U}}{\partial k}\right|_{D \rightarrow U}=-\frac{k(a-w)^{2}}{4[2(1+v)-k-r]^{3}} \leq 0, \quad \forall k \in[0,1] .
$$

Lemma 5. The downstream firm, embodying the decision of the upstream firm of not being of CSR-type (i.e., $k=0$ ), determines a positive engagement in CSR activities setting $r=r *$.

Proof: it is clear to see that:

$$
\left.\frac{\partial \pi^{D}}{\partial r}\right|_{D \rightarrow U}=\frac{[2(1+v)-k-3 r](a-w)^{2}}{8[2(1+v)-k-r]^{3}} \frac{>}{<} 0 \Leftrightarrow r \frac{<}{<} r^{*} .
$$

From Lemmas 1 to 5, the following result holds.

Result 1. Regardless of the timing of moves regarding the choice of the CSR parameter, the downstream firm always chooses some level of CSR, while the upstream firm always chooses to remain profit-seeking. 
Result 1 clearly shows the changes with respect to Brand and Grothe's (2015) results: CSR is adopted only by one firm for whatever timing of moves, while in Brand and Grothe (2015), it is adopted by both firms, but only if the timing of moves is $U \rightarrow D{ }^{5}$

Substituting the downstream firm's CSR parameter positive value $r *$ in (9) and taking into account for the choice of being only profit-seeking by the upstream firm, that is $k=0$, we obtain the equilibrium wholesale price $c *$ :

$$
c^{*}=\frac{2+5 v}{3}
$$

Substitution of $r *, k=0$, and the equilibrium wholesale price $c *$ into the expressions (10), (11), and (12) yields the equilibrium quantity, each firm's profits, and total channel profits (П):

$$
\begin{gathered}
q^{*}=\frac{3(a-w)}{8(1+v)} \\
\pi^{U *}=\frac{3(a-w)^{2}}{32(1+v)} \\
\pi^{D *}=\frac{9(a-w)^{2}}{64(1+v)} \\
\Pi^{*}=\frac{15(a-w)^{2}}{64(1+v)}
\end{gathered}
$$

Moreover, it is also straightforward to provide the expressions for the consumer surplus and total welfare:

$$
\begin{gathered}
C S^{*}=\frac{9(a-w)^{2}}{128(1+v)^{2}} \\
S W^{*}=\frac{3(10 v+13)(a-w)^{2}}{128(1+v)^{2}}
\end{gathered}
$$

\footnotetext{
${ }^{5}$ In other words, in stage 1 of the current model, the best response strategies of the upstream and downstream firms are given by $k=0$ and $r=[2(1+v)-k] / 3$, respectively. That is, choosing $k=0$ is the dominant strategy for the upstream firm. Therefore, it is apparent that the equilibrium CSR levels are going to be $k *=0$ and $r *=$ $2(1+v) / 3$, regardless of the timing of their moves. We thank a referee for this observation.
} 


\section{Comparison with the Benchmark (no CSR)}

To compare the classical bilateral monopoly in which both firms are purely profit-maximizing and a bilateral monopoly in which a socially concerned downstream firm endogenously emerges (while the upstream firm remains profit-maximizing), we report the equilibrium outcomes of the former case ${ }^{6}$ :

$$
\begin{gathered}
c=1+2 v \\
q=\frac{(a-w)}{4(1+v)} \\
\pi^{U}=\frac{(a-w)^{2}}{16(1+v)} \\
\pi^{D}=\frac{(a-w)^{2}}{8(1+v)} \\
\Pi=\frac{3(a-w)^{2}}{16(1+v)} \\
S W=\frac{(6 v+7)(a-w)^{2}}{32(1+v)^{2}} \\
C S=\frac{(a-w)^{2}}{32(1+v)^{2}}
\end{gathered}
$$

Lemma 6. The upstream firm always charges a lower input price when the downstream firm is socially concerned.

Proof: by simple comparison of (14) and (21).

The choice of the upstream firm of not being engaged in CSR activities is intuitive. Given the decreasing returns technology, every additional unit of output produced is increasingly costly. However, both revenues and costs of the upstream firm increase by the same proportion when output increases. Moreover, this cost would be supported by the downstream firm, which could actually access the input at a lower price if the upstream firm engaged in CSR. Two opposite forces must be taken into account: on the one hand, increasing the level of social

\footnotetext{
${ }^{6}$ Those outcomes are straightforwardly obtained considering that, if both firms are purely profit-maximizing, then $k=r=0$ in Eqs. (9)-(12).
} 
concern decreases the input price; on the other hand, it also increases the output of the downstream firm, which positively impacts on the revenues of the upstream firm. The different impact of those two forces can be analyzed through the total derivative of the upstream profit function with respect to $k$ :

$$
\frac{\partial \pi^{U}}{\partial k}=\frac{\partial \pi^{U}}{\partial c} \frac{\partial c}{\partial k}+\frac{\partial \pi^{U}}{\partial q} \frac{\partial q}{\partial k}=-\frac{k(a-w)^{2}}{4[2(1+v)-k-r]^{3}}<0, \quad k \in[0,1] .
$$

which shows that the negative effect of CSR on price dominates the positive impact of CSR on output expansion. Therefore, the rationale for the upstream firm to follow pure profitmaximization stems from the fact that, to attach a positive weight to consumer surplus in its objective function deeply influences in a negative manner the input price, lowering this firm's profit, all other things equal (Brand and Grothe, 2015), and making it relevant in the upstream decision not to engage in social activities.

The downstream firm strategically adopts CSR behaviors to obtain a lower input price from the upstream firm (see also Eq. (9)). The overall effect of the CSR adoption of the profitability of the downstream firm can be analyzed from the total derivative of the profit function with respect tor,

$$
\frac{d \pi^{D}}{d r}=\frac{\partial \pi^{D}}{\partial p} \frac{\stackrel{(-)}{\partial p}}{\partial q} \frac{\stackrel{\partial+}{\partial q}}{\partial r}+\frac{\partial^{(+)} \pi^{D}}{\partial q} \frac{(+)}{\partial q} \frac{\stackrel{(-)}{(+)}_{(-)}}{\partial r}+\frac{\partial \pi^{D}}{\partial c} \frac{\partial c}{\partial r}=\frac{[2(1+v)-k-3 r](a-w)^{2}}{8[2(1+v)-k-r]^{3}} \frac{>}{<} 0, \quad r \in[0,1] .
$$

The selection of a positive level of consumer-friendly CSR activities leads to an output expansion, which has several effects, both on the revenues and costs of the downstream firm. In fact, on the one hand, an increase in output has a positive effect on revenues; however, it decreases the price for final consumers, with a negative impact on revenues. On the other hand, more products for the final consumers directly increase the downstream firm's total cost; however, the strategic choice of engaging in CSR reduces the upstream firm's wholesale price of the intermediate input (which has the highest incidence on the downstream firm's total costs). As a consequence, for the downstream firm, the combined effect of the output expansion and the input price reduction at the optimal level of CSR overweighs the effect of the output price reduction, and for the upstream firm, the output expansion effect overweighs the price reduction effect, leading to the following results.

Result 2. When the endogenous choice of whether to be of CSR type is allowed in the supply chain, the emergence of downstream firms' concern over CSR realizes an enhancement of profits of each firm, industry profit, consumer surplus, and social welfare as a whole.

Proof: by simple comparison of Eqs. (16-20) and (23-27).

In particular, the main force driving the result that firms' profits are larger with CSR engagement than pure profit-maximization is double marginalization. Regardless of the timing of moves, the adoption of CSR activities by the downstream firm facilitates both lower upstream and downstream prices: the downstream firms care more about quantities, inducing in this way the upstream firm to reduce the price of the intermediate goods. Therefore, we recognize in the downstream firm's CSR engagement another mechanism (in addition to other ones well known in the literature, e.g., the two-part tariff) for reducing the intensity of the 
"double marginalization problem" in a vertical industry. As a result, both firms gain from lower overall sequential margins.

Corollary 1. While in the standard profit-seeking context the upstream firm's profits are half those of the downstream firm, under the downstream firm's endogenous choice of CSR, the profits of the upstream firm are two-thirds those of the downstream firm.

Thus, in a vertical industry with a convex technology, we note that the choice of being CSR-engaged by the downstream firm redistributes profits inside the channel between the two firms. However, although the relative profits change in favor of the upstream firm, this redistribution does not take place at the expense of the downstream firm; in fact, the downstream firm's social responsibility improves the profits of both firms. As a consequence, the total value of the channel increases, as does the welfare of consumers and society.

Corollary 2. The downstream firm's social responsibility not only generates higher profit for its owners but also leads to a Pareto-superior outcome.

Corollary 2 confirms that, given that the total welfare increases, the double marginalization problem is softened by the downstream firms' engagement in CSR.

\section{Conclusions}

This paper investigates a standard bilateral monopoly in which an upstream firm sells an intermediate product to the downstream firm, which in turn offers the final product to end consumers, allowing for an endogenous strategic choice of the level of care about the consumer surplus (consumer-friendly CSR) by the firms' owners, assuming decreasing return to the input provided by the upstream firm to the downstream firm. In other words, we revisit the results of Brand and Grothe (2015), who assume a linear bilateral monopoly. Our findings can be summarized as follows: (1) extending Brand and Grothe (2015), the achievement of higher profits for owners of all firms at the equilibrium, as the motivation behind the presence of social concerns in the firms' behaviors, also occurs in a vertical industry with decreasing returns to input; (2) it is optimal for the downstream firm - but not for the upstream firm-to be of CSR type and strongly engaged in the welfare of consumers (even being sensitive to it more than to its own profits), and this holds for whatever timing of moves with respect to the choice of CSR, reversing the findings of Brand and Grothe's (2015); (3) however, in line with those authors, not only the downstream firm's profits but also the profitseeking upstream firm's profits benefit from the consumer-friendly CSR activities of its downstream firm, and thus this situation constitutes a Pareto-superior outcome; (4) this result may explain real-world cases in which in a supply chain only the downstream firm is engaged in CSR activities; (5) this offers a policy warning about whether either downstream firms or upstream firms should be more stimulated to engage in CSR, depending on the prevailing technology (i.e., returns to scale) in the industry; (6) given that the downstream firm's choice of being CSR-engaged redistributes profits inside the marketing channel and increases its total value, then in a vertical industry with a convex technology, the empirical implication is that it should 
more often detect the presence of CSR in the downstream rather than in the upstream firm as well as both firms higher profitability when the downstream engages in CSR activities; and (7) the purely selfish owners' behavior of the downstream component of a bilateral monopoly leads to the achievement of a Pareto-improvement. This is another novel example of the reconciliation between the achievement of social objectives and the sole firm's behavior admitted by the traditional approach of economics according to Friedman (1970), that is, the maximization of profits to the shareholders. In conclusion, our paper sheds new light on whether and how firms in a marketing channel may endogenously choose to be socially concerned under a realistic technology.

Future research could perform an extra robustness check under different model specifications, relaxing the assumptions of this paper. First, it would be interesting to introduce network externalities to verify the survival of the current results. Moreover, other hypotheses such as those regarding the presence of managerial delegation and endogenous costs (such as the presence of unionized labor) within the marketing channel, either only in the upstream/ downstream company or in all channels, could be extremely intriguing for study.

Acknowledgments The authors are extremely grateful to two anonymous referees for constructive comments and suggestions that have helped them to improve significantly the quality and rigor of the paper.

\section{Impact of the downstream firm's CSR on input price elasticity of demand}

The price elasticity of demand of the upstream firm (input supplier) is

$$
\varepsilon_{U}=\frac{c}{m} \frac{d m}{d c}
$$

The upstream quantity is $m=q^{2}$. Making use of (8) and (9), one gets the expression of the price elasticity of demand as a function of the CSR parameters

$$
\varepsilon_{U}=-\frac{8 v-4 k+4-2 r}{4 v-2 k+4-2 r}<-1 .
$$

or, in absolute terms, $\left|\varepsilon_{U}\right|>1$. To see the effect of downstream CSR on upstream price elasticity of demand, differentiate $\varepsilon_{U}$ with respect tor, the downstream CSR parameter,

$$
\frac{\partial \varepsilon_{U}}{\partial r}=\frac{k-2 v}{(k+r-2-2 v)^{2}}<0
$$

i.e., the higher is the value of $r$, the lower is the value of $\varepsilon_{U}$ (the higher is the value of $\varepsilon_{U}$ in absolute terms, and therefore the more elastic is the demand).

Open Access This article is licensed under a Creative Commons Attribution 4.0 International License, which permits use, sharing, adaptation, distribution and reproduction in any medium or format, as long as you give appropriate credit to the original author(s) and the source, provide a link to the Creative Commons licence, and indicate if changes were made. The images or other third party material in this article are included in the article's Creative Commons licence, unless indicated otherwise in a credit line to the material. If material is not included in the article's Creative Commons licence and your intended use is not permitted by statutory regulation or exceeds the permitted use, you will need to obtain permission directly from the copyright holder. To view a copy of this licence, visit http://creativecommons.org/licenses/by/4.0/. 


\section{References}

Aupperle KE, Carroll AB, Hatfield JD (1985) An empirical examination of the relationship between corporate social responsibility and profitability. Acad Manag J 28(2):446-463

Bhardwaj P, Chatterjee P, Demir KD, Turut O (2018) When and how is corporate social responsibility profitable? J Bus Res 84:206-219

Bils M (1987) The cyclical behavior of marginal cost and price. Am Econ Rev 77(5):838-855

Brand B, Grothe M (2013) A note on 'corporate social responsibility and marketing channel coordination'. Res Econ 67:324-327

Brand B, Grothe M (2015) Social responsibility in a bilateral monopoly. J Econ 115:275-289

Bromiley P, Marcus A (1989) The deterrent to dubious corporate behavior: profitability, probability and safety recalls. Strateg Manag J 10(3):233-250

Chen CL, Liu Q, Li J, Wang LFS (2016) Corporate social responsibility and downstream price competition with downstream firm's effort. Int Rev Econ Financ 46:36-54

Chen YC, Hung M, Wang Y (2018) The effect of mandatory CSR disclosure on firm profitability and social externalities: evidence from China. J Account Econ 65(1):169-190

Davidson WN, Worrel DL (1988) The impact of announcements of corporate illegalities on shareholder returns. Acad Manag J 31(1):195-200

Davidson WN, Chandy PR, Cross M (1987) Large losses, risk management and stock returns in the airline industry. The Journal of Risk and Insurance 54(1):162-172

Fanti L, Buccella D (2017a) The effects of corporate social responsibility on entry. Economia e Politica Industriale - Journal of Industrial and Business Economics 44(2):259-267

Fanti L, Buccella D (2017b) Corporate social responsibility in a game theoretic context. Economia e Politica Industriale - Journal of Industrial and Business Economics 34(3):471-489

Fanti L, Buccella D (2017c) Corporate social responsibility, profits and welfare with managerial firms. Int Rev Econ 64(4):341-356

Fanti L, Buccella D (2018) Profitability of corporate social responsibility in network industries. Int Rev Econ 65(3):271-289

Fernández-Kranz D, Santaló J (2010) When necessity becomes a virtue: the effect of product market competition on corporate social responsibility. Journal of Economics \& Management Strategy 19(2): 453-487

Friedman M (1970) The social responsibility of business is to increase its profits. New York Times Magazine, September

García A, Leal M, Lee S-H (2018) Social responsibility in a bilateral monopoly with R\&D. Econ Bull 38(3): $1467-1475$

Goering GE (2007) The strategic use of managerial incentives in a non-profit firm mixed duopoly. Manag Decis Econ 28:83-91

Goering GE (2008) Welfare impacts of a non-profit firm in mixed commercial markets. Econ Syst 32:326-334

Goering GE (2012) Corporate social responsibility and marketing channel coordination. Res Econ 66(2):142148

Goering GE (2014) The profit-maximizing case for corporate social responsibility in a bilateral monopoly. Manag Decis Econ 35:493-499

Griffin JJ, Mahon JF (1997) The corporate social performance and corporate financial performance debate twenty-five years of incomparable research. Bus Soc 36(1):5-31

Heywood JS, McGinty M (2007) Convex costs and the merger paradox revisited. Economic Inquiry 45:342-349

Hino Y, Zennyo Y (2017) Corporate social responsibility and strategic relationships. Int Rev Econ 64(3):231244

Ingram RW, Frazier KB (1983) Narrative disclosures in annual reports. J Bus Res 11(1):49-60

Kopel M (2009) Strategic CSR, spillovers, and first-mover advantage. SSRN. https://doi.org/10.2139 /ssrn.1408632

Kopel M, Brand B (2012) Socially responsible firms and endogenous choice of strategic incentives. Econ Model 29(3):982-989

Kopel, M., Brand, B., 2013. Why do socially concerned firms provide low-powered incentives to their managers? SSRN working paper. Available at SSRN: https://ssrn.com/abstract=2269192 or https://doi. org/10.2139/ssrn.2269192

KPMG, 2005. KPMG international survey of corporate social responsibility reporting 2005. Available online at https://commdev.org/userfiles/files/1274_file_D2.pdf

KPMG, 2015. Currents of change: KPMG survey of corporate responsibility reporting 2015. Available online at http://www.kpmg.com/cn/en/issuesandinsights/articlespublications/pages/kpmg-survey-of-corporateresponsibility-reporting-2015-o-201511.aspx 
Lambertini L, Tampieri A (2012) Corporate social responsibility and firms ability to collude. In: Boubaker S, Nguyen DK (eds) Board directors and corporate social responsibility. Houndmills, Palgrave Macmillan UK

Lambertini L, Tampieri A (2015) Incentives, performance and desirability of socially responsible firms in a Cournot oligopoly. Econ Model 50:40-48

Lambertini L, Palestini A, Tampieri A (2016) CSR in an asymmetric duopoly with environmental externality. South Econ J 83:236-252

Leal M, García A, Lee SH (2019) Effects of integration with a consumer-friendly firm in a Cournot duopoly. Forthcoming, Journal of Industry, Competition and Trade, pp 1-18

Lee S, Jung H (2016) The effects of corporate social responsibility on profitability: the moderating roles of differentiation and outside investment. Manag Decis 54(6):1383-1406

Nakamura Y (2018) Endogenous market structures in the presence of a socially responsible firm. J Ind Compet Trade 18(3):319-348

Planer-Friedrich L, Sahm M (2018) Why firms should care for all consumers. Econ Bull 38(3):1603-1612

Planer-Friedrich L, Sahm M (2020) Strategic corporate social responsibility, imperfect competition, and market concentration. J Econ 129(1):79-101

Reuters, 2017. Automakers pledge ethical minerals sourcing for electric cars. November 29, 2017. Available online at https:/www.reuters.com/article/us-autos-minerals/automakers-pledge-ethical-minerals-sourcingfor-electric-cars-idUSKBN1DT1SK

Roman RM, Hayibor S, Agle BR (1999) The relationship between social and financial performance repainting a portrait. Bus Soc 38(1):109-125

Schramm-Klein H, Dirk Morschett D, Swoboda B (2015) Downstream firm corporate social responsibility: shedding light on CSR's impact on profit of intermediaries in marketing channels. Int J Retail Distrib Manag 43(4-5):403-431

Siegel DS, Vitaliano DF (2007) An empirical analysis of the strategic use of corporate social responsibility. J Econ Manag Strateg 16(3):773-792

Spengler JJ (1950) Vertical integration and antitrust policy. J Polit Econ 58(4):347-352

Waddock SA, Graves SB (1997) The corporate social performance-financial performance link. Strateg Manag J 18(4):303-319

Publisher's Note Springer Nature remains neutral with regard to jurisdictional claims in published maps and institutional affiliations. 